\begin{tabular}{|c|c|c|}
\hline Company & Model & Equipment \\
\hline \multicolumn{3}{|l|}{ Company A } \\
\hline & 1 & Aspiration Catheter, Microcatheter, Microwire (max 2 units each) \\
\hline & 2 & $\begin{array}{l}\text { Aspiration Catheter, Microcatheter, Microwire, Stentriever ( } \max 2 \\
\text { units each) }\end{array}$ \\
\hline \multicolumn{3}{|l|}{ Company B } \\
\hline & 1 & $\begin{array}{l}\text { Long Sheath, Diagnostic Catheter, Aspiration Catheter, } \\
\text { Microcatheter }\end{array}$ \\
\hline & 2 & $\begin{array}{l}\text { Long Sheath, Diagnostic Catheter, Aspiration Catheter, } \\
\text { Microcatheter, Stentriever }\end{array}$ \\
\hline \multicolumn{3}{|l|}{ Company C } \\
\hline & 1 & $\begin{array}{l}\text { Long Sheath, Aspiration Catheter, Microcatheter, Microwire, } \\
\text { Aspiration Tubing (at least 4) }\end{array}$ \\
\hline & 2 & $\begin{array}{l}\text { Long Sheath, Aspiration Catheter, Microcatheter, Microwire, } \\
\text { Aspiration Tubing (at least 4) + Stentriever }\end{array}$ \\
\hline & 3 & $\begin{array}{l}\text { Long Sheath, Microcatheter, Microwire, Aspiration Tubing (at least } \\
\text { 2) + Stentriever and Aspiration Catheter }\end{array}$ \\
\hline
\end{tabular}

Materials and Methods We reviewed mechanical thrombectomy cases performed at University of Pittsburgh Medical Center's (UPMC) Presbyterian and Mercy hospitals between February 2018 and August 2019, identifying those meeting criteria under capitation models negotiated with Companies $\mathrm{A}, \mathrm{B}$, and $\mathrm{C}$ (table 1). We calculated the cost of equipment for each thrombectomy using the negotiated cost for individual devices utilized and compared this sum to the total derived from cost-negotiated bundled equipment packages, resulting in the difference between non-capitated and capitated cost.

Results 107 cases were identified as meeting the criteria for capitation under the negotiated contracts; 39 cases using Company A (28 using stentrievers), 44 cases using Company B (3 using stentrievers), and 24 cases using Company C (14 using stentrievers). Total cost of equipment with the capitated model was $\$ 689,435$ compared to $\$ 891,805.50$ with the non-capitated model, a difference of $\$ 202,370.50$. This amounted to $\$ 1,891.31$ savings per case. Mean capitation model equipment costs were $\$ 1,245.26 \quad[\$ 570.00$ $\$ 7,670.00], \$ 1,110.80$ [\$165.00 - \$5,755.00], and $\$ 4,372.10$ $[-\$ 64.00-\$ 16,116.00]$ lower per case than non-capitation for Companies A, B, and C, respectively. The variation in cost savings between companies relates to multiple devices utilized that raise non-capitated costs. When combining the stentriever and non-stentriever bundles, irrespective of company, the capitated model yielded $\$ 2947 \pm 3759$ and $\$ 1124$ $\pm \$ 1330$ savings compared to the non-capitated model, respectively.

Conclusion Overall, at our institution, the negotiated capitation model yielded total cost savings, savings within each company, and with bundles including or not including stentrievers. This may serve as a model for other centers in controlling costs for patients undergoing MT for LVO.

Disclosures K. Shah: None. M. Brown: None. S. Desai: None. B. Jankowitz: 2; C; Medtronic. T. Jovin: 2; C; Stryker Neurovascular (PI DAWN - Unpaid), Blockade Medical. 5; C; Anaconda, FreeOx Biotech, Route92. 6; C; Honoraria: Cerenovus. A. Jadhav: None. B. Gross: 2; C; Medtronic, Microvention.

\section{E-045 THE TIME BURDEN OF CTP IN LATE WINDOW PRESENTERS}

$\mathrm{K} \mathrm{Wu}^{*}$, A Ouf, J Mocco, J Fifi, H Shoirah. Department of Neurosurgery, Mount Sinai Hospital, New York, NY

\subsection{6/neurintsurg-2020-SNIS.81}

Introduction After the DAWN and DEFUSE3 trials, CTP imaging became an integral part in the patient selection for endovascular treatment (EVT) in acute ischemic stroke (AIS) patients who present 6 to 24 hours within symptom onset. However, there is no consensus on the benefit of CTP evaluation as there is insufficient real-world data on the treatment delays CTP may pose. We highlight the time burden of CTP acquisition by investigating the time metrics and clinical outcomes of patients who were evaluated by CTP in the late time window.

Methods A retrospective review of all patients who underwent EVT from January 1, 2017 to March 30, 2019 was conducted. Patients were grouped into CTP and No-CTP cohorts by whether CTP was acquired prior to EVT. Descriptive statistics and nonparametric tests were performed on dependent variables. Binomial logistic regression models with baseline predictors were run on clinical outcomes. Image acquisition time was defined as the first image to the last image acquired at the central hospital. Good outcome was defined as mRS 02 while bad outcome was 3-6.

Results 88 patients presented 6 hours from symptom onset and underwent EVT for an anterior circulation occlusion, 75 of whom were evaluated with CTP. There was no statistically significant difference between the two cohorts' baseline characteristics $(p>0.05)$. Refer to table 1 for time metrics.

Abstract E-045 Table 1 Workflow time continuum

\begin{tabular}{|c|c|c|c|c|c|}
\hline Time Metric & CTP N & CTP $(\mathrm{N}=75)$ & No CTP N & No CTP $(\mathrm{N}=13)$ & p Value \\
\hline Central hospital arrival to groin puncture (min) & 75 & $75(59.0-115)$ & 13 & $45(40.5-71)$ & 0.001 \\
\hline Central hospital arrival to first image (min) & 73 & $16.3(12.9-23.5)$ & 12 & $11.6(8.9-15.6)$ & 0.026 \\
\hline Image acquisition (min) & 75 & $14.3(6.87-37.3)$ & 13 & $0.3(0.03-0.82)$ & $4.00 \times 10^{-6}$ \\
\hline СТ Acquisition Time (min) & 73 & $0.13(0.03-0.78)$ & 12 & $0.18(0.06-0.68)$ & 0.699 \\
\hline CTA Acquisition Time (min) & 36 & $0.12(0.08-0.54)$ & 2 & $0.14^{* *}$ & 0.822 \\
\hline CTP Acquisition Time (min) & 64 & $0.91(0.82-4.71)$ & 0 & n.a. & n.a. \\
\hline Last image to room arrival (min) & 73 & $19.0(9.5-36.7)$ & 12 & $11.1(7.2-35.6)$ & 0.307 \\
\hline Room arrival to groin puncture (min) & 75 & $22.8(8.9)^{*}$ & 13 & $23.2(7.3)^{*}$ & $0.881^{*}$ \\
\hline Groin puncture to $\mathrm{TICI} 2 \mathrm{~B}+(\mathrm{min})$ & 66 & $36.5(25.8-72.3)$ & 11 & $25.0(22.0-40.0)$ & 0.052 \\
\hline
\end{tabular}

All values, except Room Arrival to GP, presented as median minutes (IQR). ${ }^{*}$ Room Arrival to GP presented as mean minutes (std). ${ }^{* *}$ No IQR available because $\mathrm{n}=2$ for cell. 
Logistic regression models, with baseline predictors of age, gender, baseline NIHSS, ASPECTS and mRS scores, were run to assess whether CTP acquisition predicted intracerebral hemorrhage (ICH) presence and functional outcome at discharge and 90 days. CTP acquisition did not add any significant predictive value on functional outcomes at discharge $(p=0.439)$, at 90 days $(p=0.271)$, or on the presence of intraparenchymal hemorrhage $(p=0.626)$. Age and baseline NIHSS significantly predicted bad outcome at discharge (Age: $p=0.009$, $\mathrm{OR}=1.071$; NIHSS: $\mathrm{p}=0.003$, $\mathrm{OR}=1.183$ ) and 90 days (Age: $p=0.012, O R=1.066$; NIHSS: $p=0.023$, OR=1.121). A separate regression model using image acquisition time as a predictor of bad outcome at discharge showed a positive trend that did not meet significance $(p=0.106, O R=1.018)$.

Conclusion Our retrospective analysis highlights the prolonged time to treatment in late window presenters evaluated with CTP due to the additional image acquisition time which could include inter-imaging delays such as image processing and interpretation. Acquisition of CTP for patient selection for EVT is neither justified by added safety, as determined by the presence of $\mathrm{ICH}$, nor better functional outcomes at discharge or 90 days. Future randomized, controlled trials should evaluate the workflow time continuum and effect on outcomes for further optimization of patient selection methods for EVT in the late time window.

Disclosures K. Wu: None. A. Ouf: None. J. Mocco: None. J. Fifi: None. H. Shoirah: None.

\section{E-046 SAFETY AND EFFICACY OF CANGRELOR IN NEUROINTERVENTION}

${ }^{1} \mathrm{~A}$ Ouf*, S ElSayed, 100292, ${ }^{2} \mathrm{~N}$ Musallam, ${ }^{2} \mathrm{~N}$ Davis, ${ }^{3} \mathrm{M}$ Tanprayoon, ${ }^{2} \mathrm{~J}$ Fifi, ${ }^{2} \mathrm{~J}$ Mocco, ${ }^{2} \mathrm{H}$ Shoirah. ${ }^{1}$ Neurosurgery, Mount Sinai Hospital, Brooklyn, NY; ${ }^{2}$ Neurosurgery, Mount Sinai Hospital, New york, NY; ${ }^{3}$ Neurosurgery, Mount Sinai Queens, Queens, NY

\subsection{6/neurintsurg-2020-SNIS.82}

Background Acute ischemic stroke with tandem cervical and intracranial disease is a morbid entity. Despite the advances in endovascular therapies (EVT), a significant percentage of treated patients develop symptomatic intracranial hemorrhagic conversion. The risk increases with the use of intravenous Glycoprotein IIb/IIIa inhibitors (GPI) during acute stenting. Cangrelor is a novel intravenous P2Y12 inhibitor that has been established as an effective alternative to GPI in cardiac interventions. However, little is known about the safety and efficacy of Cangrelor in neuro-interventions.

Methods This is a series of all cerebrovascular patients treated with EVT in whom Cangrelor was used between January 2019 and August 2019 in a single tertiary center. We describe patient characteristics, technical and pharmacological details and outcomes.

Results Our cohort included 16 patients treated with Cangrelor, $56.3 \%$ were male patients, and the median age was 66 years $(\mathrm{IQR}=18)$. The majority of patients $(75 \%)$ were stroke cases, while $3(18.8 \%)$ were diagnosed with aneursyms and 1 (6.3\%) received Cangrelor post-op. Out of the 12 stroke patients, 7 patients had a tandem occlusion and 5 patients had intracranial atherosclerotic disease (ICAD) of a single vessel (table 1). Standard dosing was used in all patients, with median bolus of $2.36 \mathrm{mg}(\mathrm{IQR}=0.52)$ and a median infusion dose of $58.8 \mathrm{mg}(\mathrm{IQR}=84)$. Platelet reactivity unit test (PRU) was performed in 7 patients, 10-30 minutes after the bolus dose with a median value of $7(\mathrm{IQR}=63) .62 .5 \%$ of patients were transitioned to clopidogrel and $25 \%$ to ticagrelor. All patients had follow-up vessel imaging 2 days after the procedure. Only 2 patients experienced re-occlusion of their stents while the rest of the stents remained patent. Only 1 patient experienced a symptomatic subarachnoid hemorrhage. Median cost of Cangrelor was $\$ 1796$ per patient.

M, Male; F, female; icad, Intracranial atherosclerotic disease; L, Left; r, right; ica, internal carotid artery; cica, cervical internal carotid artery; va, vertebral artery; m1-3, m1-3 segments of the middle cerebral artery; sah, subarachnoid hemorrhage.

Conclusions Cangrelor has a safer and more effective profile in comparison with GPI in patients undergoing emergent endovascular treatment of cerebrovascular pathologies

\section{Abstract 0-046 Table 1 Individual patient characteristics}

\begin{tabular}{|c|c|c|c|c|c|c|c|c|c|}
\hline Case ID & Demographics & Indication & \multicolumn{3}{|c|}{ Target Vessels } & Transition Agent & tpA & Complications & Stent Patency \\
\hline 1 & $70-75 \mathrm{M}$ & ICAD (R VA) & \multicolumn{3}{|c|}{ R VA stent } & Brilinta & No & None & patent \\
\hline 2 & $70-75 \mathrm{M}$ & Tandem occlusion & \multicolumn{3}{|c|}{ R clCA stent,M1 thrombectomy } & Plavix & No & None & patent \\
\hline 3 & $50-55 \mathrm{~F}$ & Tandem occlusion & \multicolumn{3}{|c|}{ L ICA stent,M1 thrombectomy } & Plavix & No & None & patent \\
\hline 4 & $65-70 \mathrm{~F}$ & Tandem occlusion & \multicolumn{3}{|c|}{ L ICA stent, M1 thrombectomy } & Plavix & Yes & None & patent \\
\hline 5 & $50-55 \mathrm{M}$ & AIS - ICAD & \multicolumn{3}{|l|}{ Basilar } & Plavix & No & Occlusion & occluded \\
\hline 6 & $55-60 \mathrm{~F}$ & Tandem occlusion & \multicolumn{3}{|c|}{ R clCA stent,M3 thrombectomy } & Plavix & No & None & patent \\
\hline 7 & $40-45 \mathrm{M}$ & AIS - ICAD & \multicolumn{3}{|l|}{ L M2 } & Brilinta & Yes & None & $\mathrm{N} / \mathrm{A}$ \\
\hline 8 & $60-65 \mathrm{~F}$ & Tandem occlusion & \multicolumn{3}{|c|}{ L ICA stent,M1 thrombectomy } & Plavix & Yes & None & patent \\
\hline 11 & $85-90 \mathrm{M}$ & ICAD (Basilar occlusion) & \multicolumn{3}{|c|}{ Basilar a. } & Brilinta & No & None & patent \\
\hline 13 & $65-70 \mathrm{M}$ & Tandem occlusion & \multicolumn{3}{|c|}{ R ICA stent,M1 thrombectomy } & Plavix & No & None & Patent \\
\hline 14 & $85-60 \mathrm{M}$ & ICAD & \multicolumn{3}{|l|}{ R ICA } & Plavix & No & None & patent \\
\hline 15 & $95-100 \mathrm{~F}$ & latrogenic Dissection & \multicolumn{3}{|l|}{ L clCA } & None & Yes & Symptomatic SAH & N/A \\
\hline \multirow[t]{2}{*}{16} & $65-70 \mathrm{M}$ & Post-operative sub-occlusive thrombus & \multicolumn{3}{|l|}{ R M1 } & None & No & None & N/A \\
\hline & & & & Hunt \& Hess & Modified Fisher & & & & \\
\hline 9 & $45-50 \mathrm{M}$ & Ruptured R ICA aneurysm & R ICA & Grade 1 & Group 3 & Plavix & No & None & patent \\
\hline 10 & $65-70 \mathrm{~F}$ & Ruptured L MCA aneurysm & L MCA & Grade 2 & Group 1 & Plavix & No & None & patent \\
\hline 12 & $55-60 \mathrm{~F}$ & Symptomatic R supra-clinoid ICA aneurysm & R ICA & N/A & $\mathrm{N} / \mathrm{A}$ & Brilinta & No & Occlusion & Occluded \\
\hline
\end{tabular}

